\title{
Análise da corrosão do aço 1020 por meio do processamento de sinais
}

\author{
Alves, L. M. ${ }^{1}$; Prado, A. R. ${ }^{1}$; Cavalieri, D.C. ${ }^{1}$; Pereira, F. G. ${ }^{1}$; Oliveira, J. P. ${ }^{2}$ \\ 1 Instituto Federal do Espírito Santo, Serra, ES, Brasil \\ 2 Universidade Federal do Espírito Santo, Vitória, ES, Brasil
}

\begin{abstract}
Resumo
As técnicas de monitoramento e análise da corrosão estão se desenvolvendo a cada dia, entretanto, ainda é um universo pouco explorado. Nesse sentido, o processamento de sinais pode ser uma ferramenta poderosa para a análise da corrosão metálica. Assim, este trabalho está propõe um método de análise de corrosão metálica através da aplicação da Transformada de Fourier nos sinais de tensão elétrica provenientes do ruído eletroquímico em um eletrodo de aço 1020. Através da análise matemática dos sinais obtidos, foi possível verificar o comportamento da passivação do aço, sendo possível diferenciar e identificar se o aço está sofrendo degradação ou proteção, validando o desenvolvimento do método proposto.
\end{abstract}

Palavras chaves: Corrosão, Ruído Eletroquímico, Processamento de Sinais.

\section{Introdução}

A corrosão é um processo espontâneo caracterizado por reações químicas e eletroquímicas que ocorrem na superfície de materiais sólidos. A técnica de análise da corrosão por meio do ruído eletroquímico é muito promissora e consiste na interpretação das variações espontâneas e de pequena amplitude, de corrente ou de tensão ao longo do tempo [1]. Nesse trabalho foram utilizados os dados provenientes das flutuações da tensão medidos através do potencial de circuito aberto para a aplicação de técnicas de processamento de sinais, a fim de propor um método de análise de corrosão simples e de baixo custo.

\section{Materiais e Métodos}

Nesse estudo foram utilizadas quatro placas de aço 1020, uma solução de cloreto de potássio ( $\mathrm{KCl}$, Cromoline) com concentração de 20 mil ppm, uma solução de hidróxido de sódio ( $\mathrm{NaOH}$, Cromoline) com $\mathrm{pH} 11$, eletrodo de referência $\mathrm{Ag} / \mathrm{AgCl}$ e potenciostato Autolab Modelo PGSTAT101 Metrohm®.

Para o desenvolvimento do trabalho, foram utilizadas placas de aço $1020 \mathrm{com}$ áreas expostas iguais a 18 $\mathrm{mm}^{2}$ devidamente isoladas com resina epóxi. A escolha do aço 1020 justifica-se por ser de baixo custo e largamente utilizado na indústria. Para a realização dos experimentos foi montada uma célula eletroquímica com posição definida para os eletrodos de aço (distância entre os eletrodos: $5 \mathrm{~mm}$ ) e o eletrodo de referência.

Com o auxílio do potenciostato foi possível medir e arquivar as variações temporais do potencial de circuito aberto entre os eletrodos idênticos de aço 1020. Os ensaios de ruído eletroquímico foram realizados em duas soluções aquosas diferentes, com o intuito de identificar dois comportamentos distintos do metal. Uma das soluções era composta de cloreto de potássio a 20 mil ppm, onde o material apresentou o comportamento de corrosão e a outra com $\mathrm{NaOH}$, onde o aço apresentou o comportamento de passivação pela formação de uma camada de hidróxido de ferro (III). Através de ferramentas de processamento de sinais como a transformada de Fourier e a Densidade Espectral de Potência foi possível estudar e distinguir o comportamento do metal nos dois meios aquosos distintos. Para verificar a influência temporal nos processos as analises foram realizadas por 30,60 e 90 minutos.

\section{Resultados e Discussões}

$\mathrm{Na}$ Figura 1 são apresentados os dados de ruído eletroquímico do aço 1020 na solução de cloreto e hidróxido a $\mathrm{pH} 11$. 


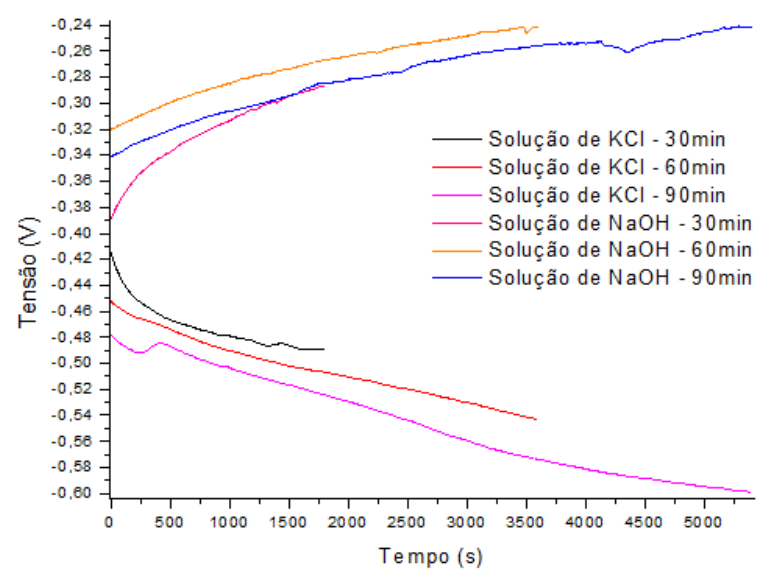

Figura 1: Dados de ruído eletroquímico do aço 1020.

Nota-se claramente as diferenças do comportamento entre esses dois meios eletrolíticos. O processo de corrosão promove a redução do potencial do sistema, já a passivação promove a elevação do sinal devido a barreira de potencial gerada pela adesão do filme de hidróxido de ferro (III) sobre o aço.

Em seguida foi utilizada a Transformada de Fourier com o objetivo de extrair informações dos dados de ruído eletroquímico. Tal transformação permite a análise dos dados no domínio da frequência. [3]

A Figura 2 mostra os resultados da transformada de Fourier sobre os dados do ruído eletroquímico. Com essa informação é possível estabelecer um parâmetro relacionado ao ponto de invariabilidade dos sinais estudados, sendo esse parâmetro a intensidade da componente de frequência zero.
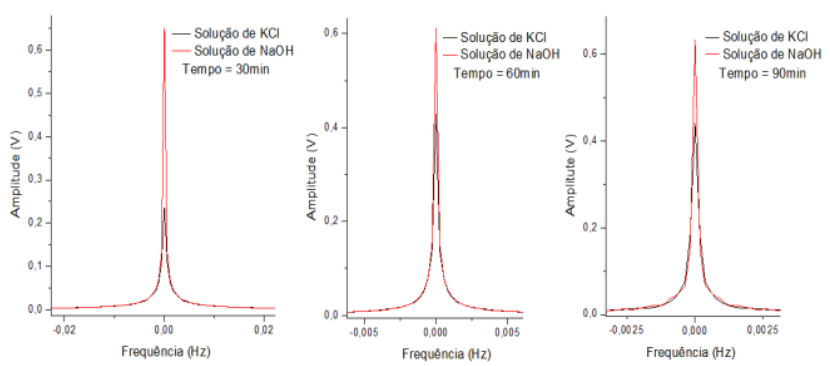

Figura 2: Transformada de Fourier sobre o Ruído Eletroquímico

Em processos corrosivos, a perda de massa do aço está relacionada com os processos oscilatórios de oxidação e redução, que provocam a variação na corrente e na tensão. Dessa forma, metais que apresentam uma maior resistência à corrosão, possuem maiores amplitudes na magnitude de seu sinal na frequência zero, indicando maior invariabilidade do sinal [2]. Comparando-se os resultados, percebe-se que no aço imerso em solução de $\mathrm{NaOH}$ (curva em vermelho) há a formação de camada passivadora, tornando o aço mais resistente à corrosão, pois sua amplitude na frequência zero é maior que a do aço imerso em solução de $\mathrm{KCl}$. A equação abaixo apresenta outra ferramenta de análise, denominada Densidade Espectral de Potência (PSD Power Spectral Density).

$S x x(f)=\lim _{t_{0} \rightarrow=x} \frac{\left.E\left[\mid x_{x_{0}}(f)\right]^{2}\right]}{2 t_{0}}$

Essa ferramenta permite analisar o conteúdo de potência de um sinal em relação à frequência [3]. Apesar de as placas de aço 1020 possuírem a mesma composição química, através da análise do PSD é possível observar a diferença de comportamento entre as soluções. Nesse caso, o PSD revela a maior invariabilidade do aço presente na solução de hidróxido, conforme observado na curva em vermelho na Figura 3, pois revela um aumento da sua potência na frequência zero.
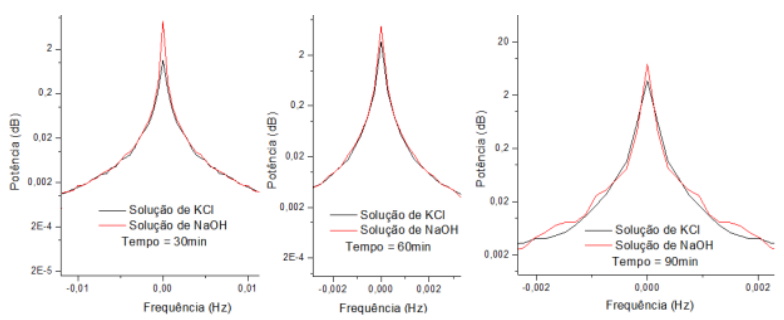

Figura 3: Densidade Espectral de Potência do Ruído Eletroquímico.

Essa elevação da potência é esperada devido à formação da camada passivadora resultante da ação dos íons provenientes da dissolução da base em meio aquoso, que formam uma espécie de barreira de proteção que dificulta a troca de elétrons presentes no aço com o meio.

\section{Considerações finais}

Com os dados obtidos nesse trabalho é possível constatar que a técnica de processamento de sinais apresenta grande perspectivas de contribuições ao estudo eletroquímico de corrosão em processos industriais e sem elevado custo operacional.

\section{Referências}

[1] Zaveri, N.; Sun, R.; Zufelt, N.; Zhou, A.; Chen, Y. Electrochimica Acta, v. 52, p. 5795-5807, 2007.

[2] Cottis, R. A.; Al-Awadhi, M. A. A.; Al-Mazeedi, H.; Turgoose, S. Electrochimica Acta, v. 46, p. 3665-3674, 2001.

[3] Loto, C. A.; Int. J. Electrochem. Sci., v. 7, p. 9248 9270, 2012. 